LAWRENCE LIVERMORE NATIONAL LABORATORY
Novel Application of Fiber Optic Sensor for Characterizing Real-Time Contaminant Transport in Rapid Storm Runoff

C.G. Campbell, J. Richards, M. Zavarin, P. Stratton, J. Coty, D. Laycak

February 7, 2003 


\section{DISCLAIMER}

This document was prepared as an account of work sponsored by an agency of the United States Government. Neither the United States Government nor the University of California nor any of their employees, makes any warranty, express or implied, or assumes any legal liability or responsibility for the accuracy, completeness, or usefulness of any information, apparatus, product, or process disclosed, or represents that its use would not infringe privately owned rights. Reference herein to any specific commercial product, process, or service by trade name, trademark, manufacturer, or otherwise, does not necessarily constitute or imply its endorsement, recommendation, or favoring by the United States Government or the University of California. The views and opinions of authors expressed herein do not necessarily state or reflect those of the United States Government or the University of California, and shall not be used for advertising or product endorsement purposes.

This is a preprint of a paper intended for publication in a journal or proceedings. Since changes may be made before publication, this preprint is made available with the understanding that it will not be cited or reproduced without the permission of the author. 


\title{
Novel Application of Fiber Optic Sensor for Characterizing Real-time Contaminant Transport in Rapid Storm Runoff
}

\author{
02-ERD-055 \\ Chris G. Campbell, Jim Richards, Mavrik Zavarin, Paul Stratton, Jessie Coty, \& \\ Danny Laycak
}

\section{INTRODUCTION}

Concern over suspended sediment in storm water runoff continues to increase in both government and industrial institutions. The US Department of Energy (DOE) Office of Regulatory Affairs in 2002 started a Total Maximum Daily Load (TMDL) working group to focus on the looming impact of the listing of water bodies as "impaired" under the Clean Water Act Section 303(d). A TMDL allocates the total mass of a specific contaminant that can be discharged from a permitted industrial facility. Recent discussions with this group have revealed a few common contaminants that are potential candidates for listing around DOE facilities including: metals (e.g. mercury), PCBs, and other organic compounds like dioxins and pesticides. Under the current regulations it is the total concentration of these contaminants in water that is limited by TMDLs, not just the dissolved portions. This is significant as all the previously listed contaminants are more likely to be sorbed to suspended sediments than they are to be dissolved in storm water runoff. This means that in order to understand -- even correctly estimate -- the total load of these contaminants, accurate estimates of the suspended sediment loads are necessary.

Various methods are used to estimate suspended sediments including: flow proportioned samplers, sampling pumps, optical back scattering (OBS) devices, and acoustic back scattering (ABS) devices (Wren, et al., 2000). Unfortunately these devices are not accurate, are subject to numerous confounding signals, and either lack the sampling resolution necessary in storm runoff or are ridiculously expensive. This is because the technologies that provide the necessary temporal resolution are based on the back scattering of light and sound waves, which only directly measures turbidity. Turbidity, by definition, is the cloudiness of water, or the extent to which light is scattered in the water. In storm water runoff, turbidity may depend on many factors in addition to suspended sediment including: organic matter and other floating debris, algae, air bubbles, and even water discoloration. While some of these issues can be removed in when using OBS or ABS devices, the measurement is still not a true value of suspended sediment in the water column.

In response to these problems in characterizing water quality, we have begun developing a Fiber-optic In-stream Technology (FIT) based on remote fiber optic technology (Krohn, 1988) for continuous measurements of suspended sediment load in surface waterways. Our goals are to develop and apply an inexpensive, low power requirement fiber optic sensor that will collect real-time measurements of sediment loads in surface water, for remote monitoring of surface water quality. Then from this prototype device other chemical measurement capacities may be developed. Our specific research goals included to: 
1.) Design and assemble a prototype FIT to measure suspended sediment particles,

2.) Develop a data acquisition and analysis approach,

3.) Compare the prototype FIT to commercially available turbidity probes, and

4.) Create alternative designs that provide greater measurement capacity.

\section{APPROACH AND ACCOMPLISHMENTS}

Numerous fiber optic based devices have been developed recently for water quality measurements in environmental applications (Ghodrati et al., 2000; Campbell et al., 1999; Hoffman et al., 1996; Motellier et al., 1995; Reichert et al., 1991; Nielsen et al. 1991; Chudyk et al., 1985). The FIT includes a fiber optic probe housed in a flow-through device where stream water may enter and exit. A constant light source (in this case a light emitting diode - LED or a red light laser) will be used in a fiber optic array. Light will exit the source fiber where water flows between the source and the detector fiber optic cables. Using a photodetector, light intensity is transformed into an electrical signal that may be recorded on any commercially available data logger. Relationships may then be developed to calibrate changes in the measurement signal to suspended sediments.

A representation of the concept and design may be found in Figure 1. The ultimate goal was to develop a robust sensor that can be used to collect point measurements of suspended sediment in stream channels. A number of these point measurements could then be applied to collect real-time measurements at various depths and locations in the channel. The sensor would be designed to be compatible with wireless remote data acquisition and remote operation. The design selected included nested linear arrays of fiber optic cables. The nest design allows for each group of fiber optic detector to be focused on the quantification of specific particle size classes.

As mentioned in the previous section, the tasks necessary to completing the design and testing of this approach included to: (1) examine a simplified prototype FIT based on light absorbance measurements with a linear fiber optic array and single detector, (2) consider how data acquisition and analysis would occur, (3) compare the performance of the prototype to commercially available technologies, (4) feed this information back into the design to create and better sediment sensor. The following sections discuss these tasks and provide some preliminary results and accomplishments during the mid-year 2002 funding period. 

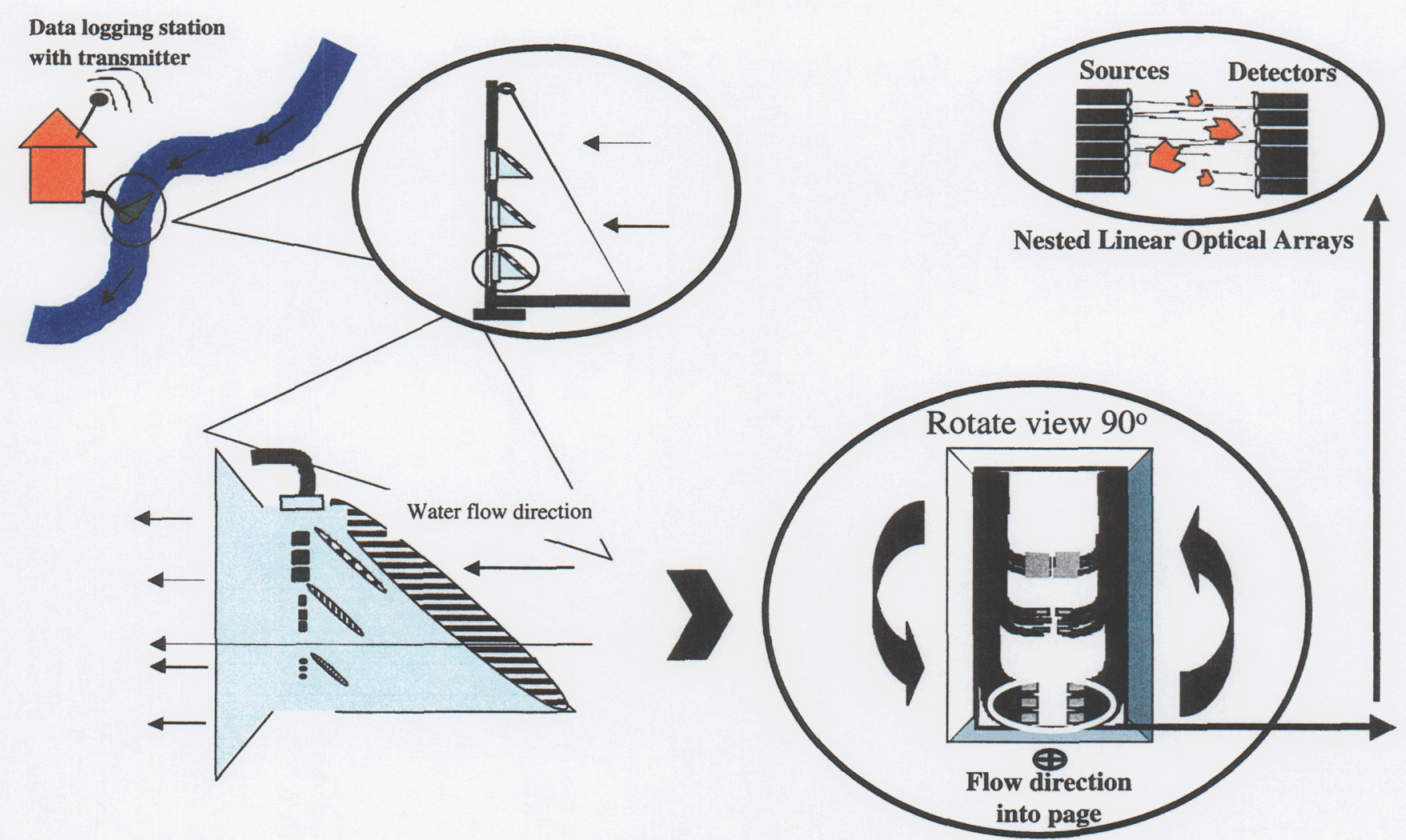

Figure 1: Design and potential application of the FIT sediment sensor

\section{1.) Designing and assembling a prototype FIT to measure suspended sediment particles}

The Fiber optic In-stream Technology (FIT) probe was designed to collect information on light absorption or shadowing. Using the FIT, the light intensity (amount of light) reaching a detector from a constant source will be measured. Soil particles will have an absorbing or "shadowing" effect by blocking some portion of the light connection between the source and detector based on particle size. In the nested design shown in Figure 1, a number of different diameter fiber optic cables will be used to focus in on different particle sizes.

A simple measurement of the shadowing will allow us to estimate the suspended solids as described by the Beer-Lambert Law. However, by using multiple fiber optic cables of various diameters (see Figure 1), the FIT will also be capable of measuring particle sizes of the larger soil particles (course sands [ $2000-200 \mathrm{~mm}$ dia.], fine sand [325-50 $\mathrm{mm}$ dia.], and course silts [75 $-20 \mathrm{~mm}$ dia.]). Therefore the final measurement of shadowing, excluding all the effects from the larger size classes can be assumed to be clay sized particles.

Initially a prototype FIT was constructed using a red light emitting diode (LED) as the source, fiber optic bundles spread into a linear array on one end at the source and detector cables, and finally two different detectors were tested including a FLUKE (Everett, WA) optical multimeter and Ocean Optics (Dunedin, FL) portable spectrophotometer (Figure 2). Both of these detectors connected to a notebook computer for data collection and analysis. Testing and comparison of the FIT to commercially available devices used for suspended sediment measurements are discussed in task 3. The storm water simulator identified in Figure 2 will also be described in task 3 . 




Figure 2: Diagram of the simple prototype FIT probe

\section{2.) Developing the data acquisition and analysis approach}

As with any sensor the design of the output signal, as well as, data collection, analysis and storage are as important to the design as the sensor technology. As the light absorbance measurements are reasonably simple the more difficult task was to design multiple sources and detectors and collect all the data in a manner which allows for rapid analysis. To do this we needed to determine, within defined thresholds, if the light from the sources is blocked before getting to the detectors. In this situation the entire programming can be set up to run as a digital system. This would greatly increase the speed and ease of data analysis.

The digital data collection and analysis system would work as follows. The light source would be constant with the detectors registering a constant background based on spacing distance from source to detector and the properties of the water moving in a stream at baseflow conditions. When a sediment particle moves into the space between the source and detector the light with be all or partially blocked from reaching the detector (Figure 3). The light transmission signal for particles passing in between the linear array of uniquely coupled sources and detectors would look like the graph in Figure $\mathbf{3}$ for each individual source-detector pair. Therefore with multiple source-detector pairs in each linear array and then nested linear arrays to focus on different particle sizes could result in a large amount of data collection and processing. To avoid this problem the signal can be interpreted at a digital system, where a threshold is defined above which the signal is considered "on" and below which it is considered "off". This approach not only allows for more data collection and faster analysis, it also provided an additional interpretive advantage. The data output can be examined in a hierarchical manner where on the first tier the light to individual detectors are blocked, and on the second tier places where two detectors are blocked may be identified, and so on as illustrated in the figure. The advantage is that information can be gathered not only on total sediment loading, but also on 
particle sizes and even shapes. This unique approach to suspended sediment characterization could have several advantages not the least of which is for estimated the specific surface area available to adsorb metals and organic contaminants.
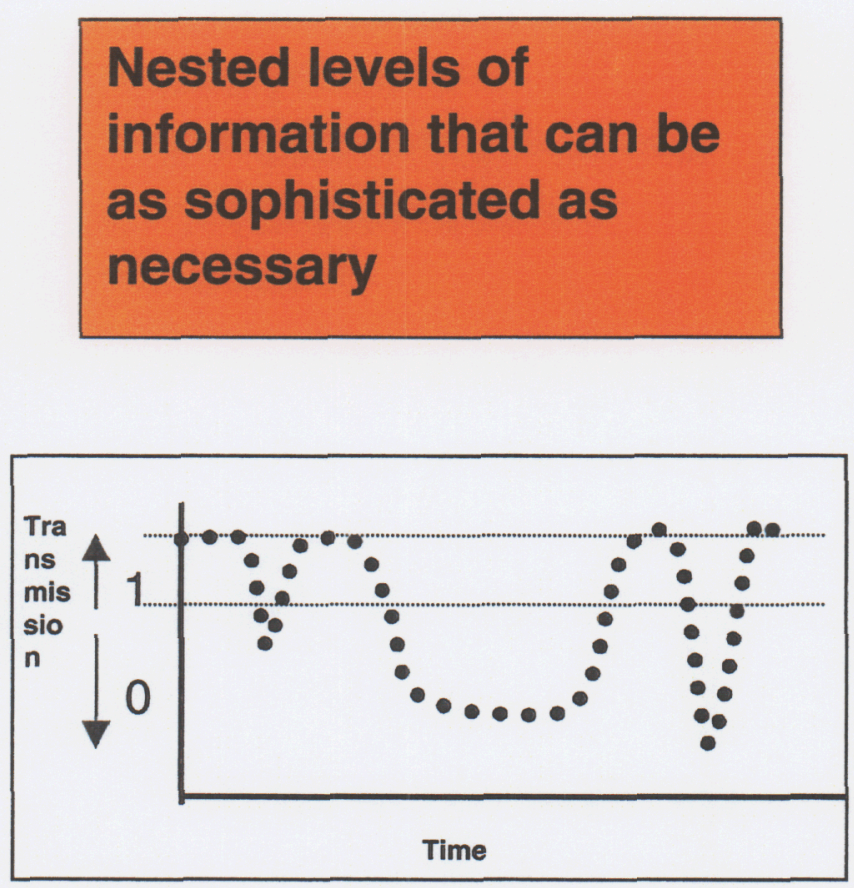

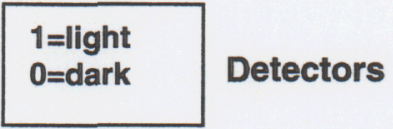

Sources

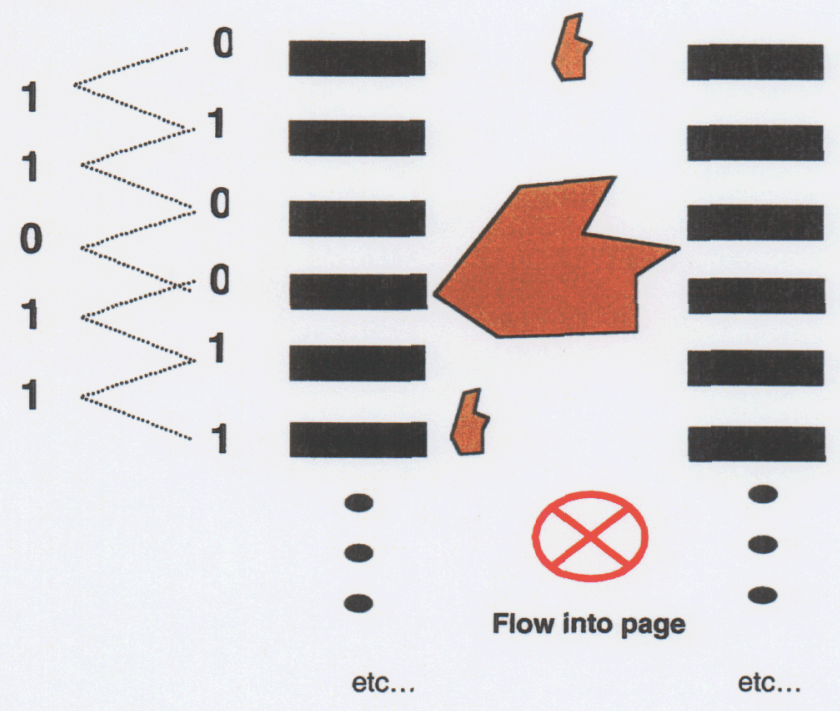

\section{Linear Optical Array}

Figure 3: Digital data acquisition and analysis design

\section{3.) Comparing the prototype FIT to commercially available turbidity probes}

After the FIT prototype had been fabricated and tested, we designed a study to compare its performance for suspend Sediment measurement to commercially available turbidity probes. For this study a storm water simulator (SWS) or mixing chamber was constructed (Figure 4). Both the FIT and turbidity sensors installed in to the SWS through removable side panels cut to specifically suit the sensors. The performance, accuracy, and precision of the sensors were compared in various sediment loading ranges selected to coincide with those observed in storm water runoff $(0 \mathrm{~g} / \mathrm{L}$ to $10 \mathrm{~g} / \mathrm{L}$ or ppt). In addition the particle size dependence of these measurements were examined by using different particle size ranges $(<45,75-150,150-250,250-$ $300,710-1000 \mu \mathrm{m})($ data not shown). The performance of each of these sensors was examined under these conditions. 

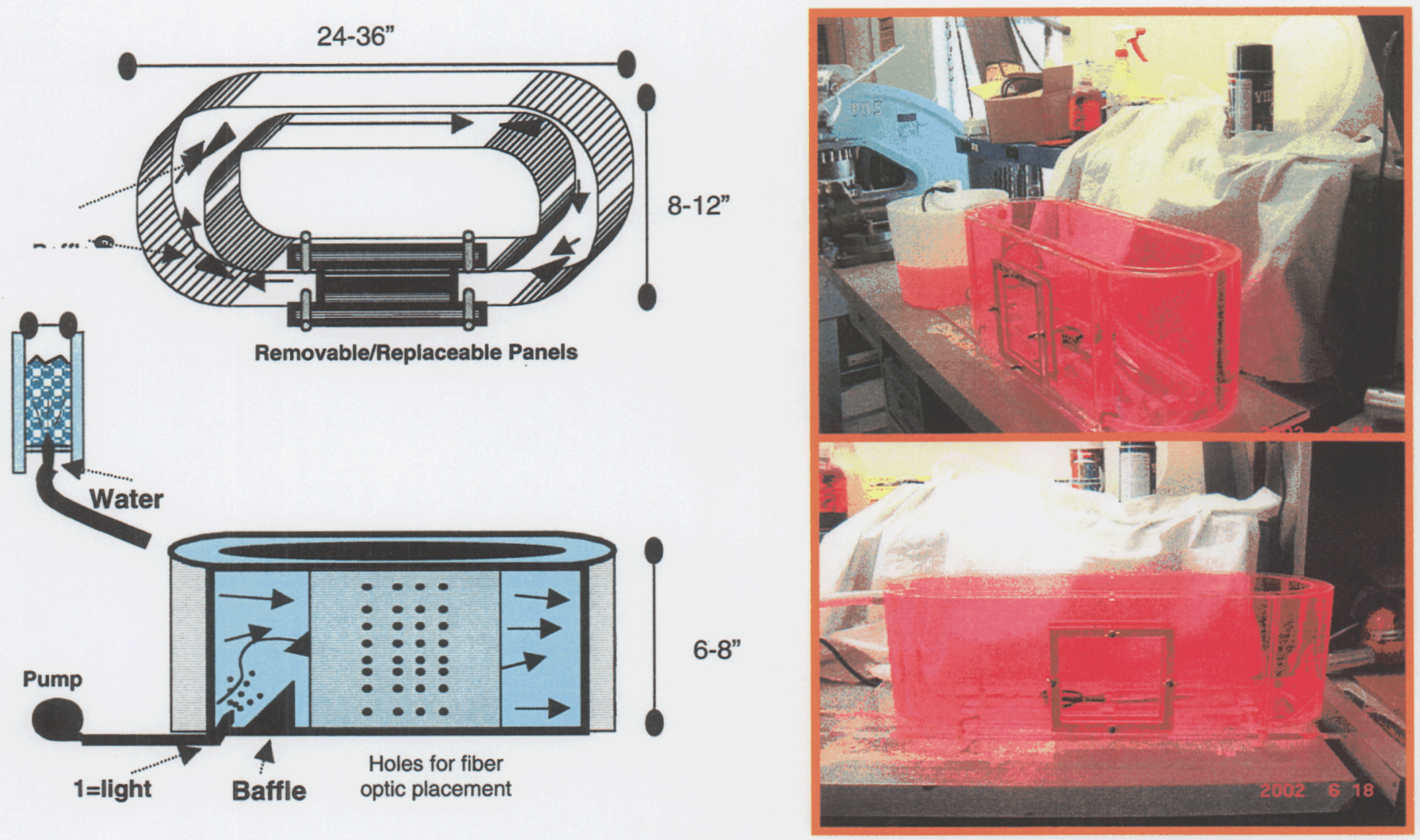

Figure 4: Storm water simulator for FIT calibration and comparison for suspended sediment measurements

The results demonstrate the advantage the simple prototype FIT has, over the commercially available devices in measuring sediment loading. Turbidity measurements are based on light scattering that is highly sensitive to particle size and type of material. The turbidity probes selected were the Lamotte portable turbidity meter and Global Water turbidity logger. Both devices use US EPA approved standard methods for turbidity measurement and turbidity is currently the only real-time measurement that is collected to correlate to suspended sediment loading. Readings from both turbidity devices reach a maximum before the $5.0 \mathrm{~g} / \mathrm{L}$ sediment load, while the LLNL FIT doesn't reach a maximum reading before $10.0 \mathrm{~g} / \mathrm{L}$ (Figure 5). All the data could be approximated with a linear calibration to suspended sediment load, that therefore simplifies calibration procedures. However, the precision of the measurements is much better in the LLNL FIT. Ten measurements were collected for each sediment load (x-axis) for each device and the variability translates in to greater than $20 \%$ for each of the turbidity devices and less that $10 \%$ for the LLNL FIT using linear calibrations. 




Figure 5: Data collected from the LLNL prototype FIT and Global Water and Lamotte turbidity probes for suspended sediment loading from 0.0 to $10.0 \mathrm{~g} / \mathrm{L}$. The LLNL FIT and Global Water sensors were installed in the storm water simulator and water samples were used for the Lamotte meter.

\section{4.) Creating alternative designs that provide greater measurement capacity}

Given the success with the prototype FIT, the project continued to design the more detailed FIT that includes the uniquely paired source and detector and the digital data collection and analysis approach. The schematic design and resulting set up of the equipment from Thorlabs Inc. (Newton, NJ) are in Figures 6 and 7. Using this set up will allow us to examine all the design issues listed in Table 1 in detail. In the future funding will be sought to focus on these system design issues to create a second generation prototype to test for measuring both particle sizes and suspended sediment loading. Collaborations have already begun with the University of California at Irvine to continue improving the FIT suspended sediment sensor.

Table 1: System components to examine for fiber optic measurements

\begin{tabular}{|l|}
\hline Fiber diameter \\
\hline Numerical aperture of source and detector \\
\hline Light intensity (power) \\
\hline Transmission or scattering measurements \\
\hline Light focusing traditional or GRIN (GRaded INdex) lenses \\
\hline Distance between fibers \\
\hline Fiber arrangement (linear, circular ) \\
\hline Light filters (focusing bandwidths) both types and spatial arrangement \\
\hline Multiplexing options (for both wavelengths and fluorescence) \\
\hline Data logging and temporal resolution \\
\hline Output signal analysis \\
\hline 1 vs. 2 dimensional measurement zone design \\
\hline Field application design parameters \\
\hline
\end{tabular}




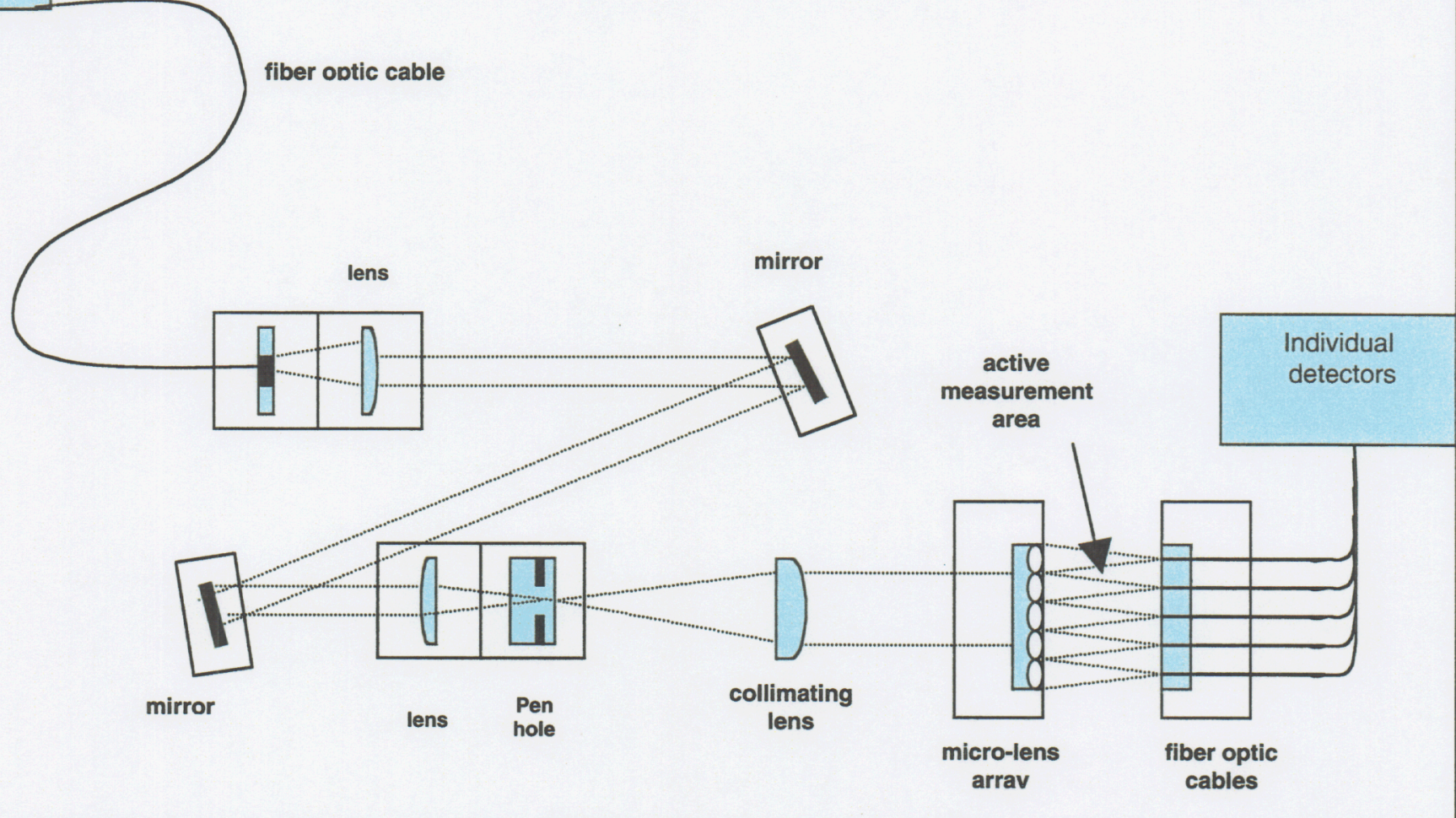

Figure 6: FIT design for detailed examination of design components

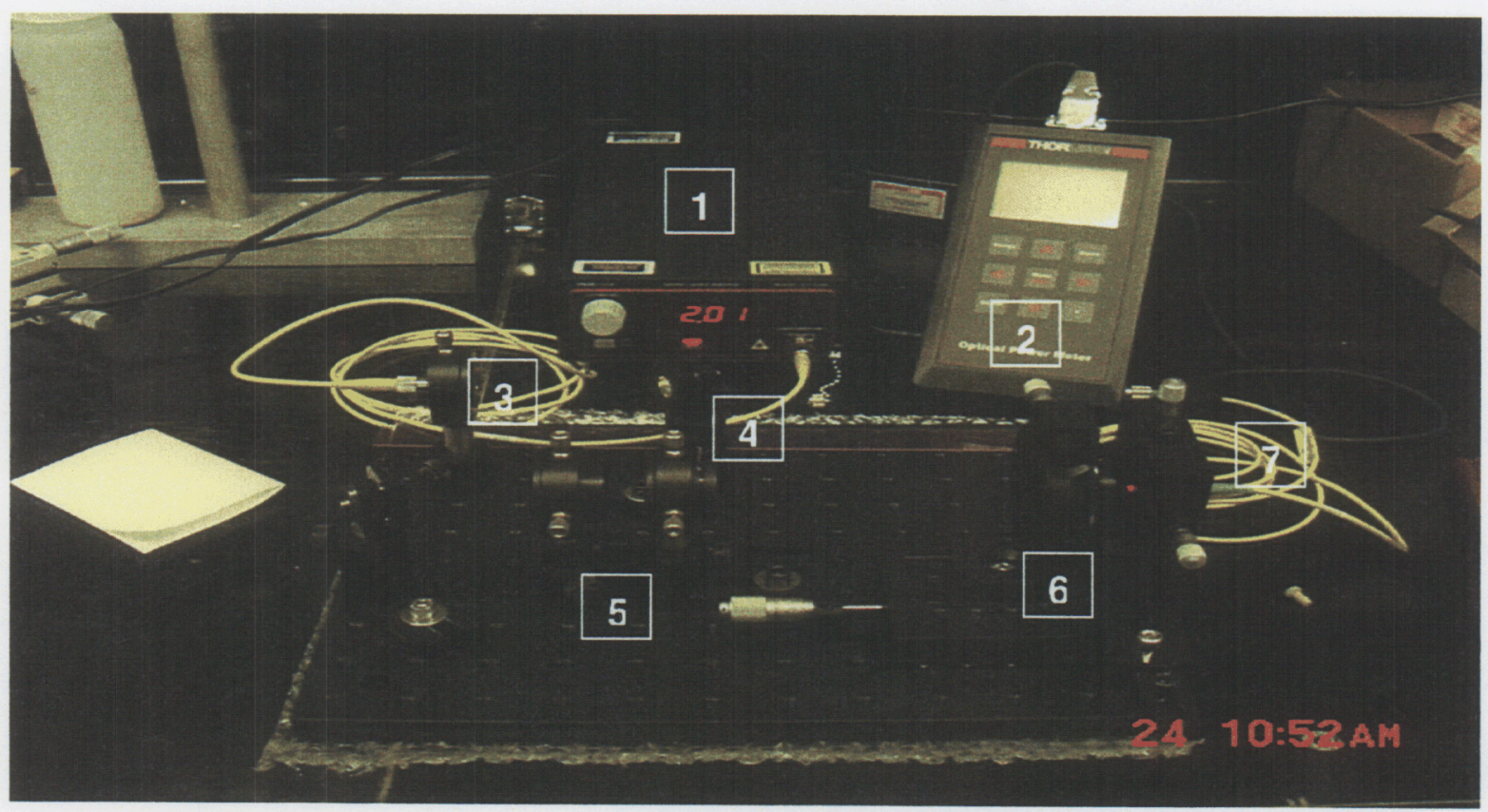

1. Laser light source

2. Light power meter

3. Collimating lens
Key:

4. Directional mirrors

5. Various lenses and pen-hole

6. Micro-lens array

7. Detection cables

Figure 7: Photograph of the detailed FIT design (equipment from ThorLabs Inc.

Netwon, NJ). 


\section{REFERENCES}

Campbell, CG, M. Ghodrati, F. Garrido. 1999. Comparison of time domain reflectometry, fiber optic mini-probes, and solution samplers for real time measurement of solute transport in soil. Soil Science. 164 (3):156-170.

Chudyk, W.A., M.C. Carraba, and J.E. Kenny. 1985. Remote detection of groundwater contaminants using far-ultraviolet laser-induced fluorescence. Anal. Chem. 57:1237-1242.

Ghodrati, M., F. Garrido, C.G. Campbell, and M. Chendorain. 2000. A multiplexed fiber optic miniprobe system for small scale measurements of solute transport in soil. Journal of Environmental Quality. 29(2): 540-550.

Hoffman, F. D. Ronen, H. Rosin, F. Milanovich. 1996. Novel use of a fiber-optic-based trichloroethylene sensor in a column retardation experiment. Talanta. 43: 681-689.

Krohn, M. and B.B. Jorgensen. 1988. Fiber optic scalar sensors: Fundamentals and applications. Instrument Society of America. Research Triangle Park, NC. 193-209.

Motellier, S., M. H. Noire, H. Pitsch, B. Dureault. 1995. pH determination of clay interstitial water using a fiber-optic sensor. Sensor and actuators B29 345-352.

Neilsen, J.M., G.F. Pinder, T.J. Kulp, S.M. Angel. 1991. Investigation of dispersion in porous media using fiber-optic technology. Water Resources Research. 10: 2743-2749.

Reichert, J., W. Sellien, and H. J. Ache. 1991. Development of fiber-optic sensor for the detection of ammonium in environmental waters. Sensors and Actuators A, 25-27: 481-482.

Wagner, BJ; Harvey, JW. 1997. Experimental design for estimating parameters of rate-limited mass transfer: Analysis of stream tracer studies. Water Resources Research. 33(N7):17311741.

Wren, DG; Barkdoll, BD; Kuhnle, RA; Derrow, RW. 2000. Field techniques for suspendedsediment measurement. J. Hydraul. Eng-ASCE, 126(N2):97-104. 
University of California

Lawrence Livermore National Laboratory

Technical Information Department

Livermore, CA 94551 